\title{
PROBABLE TRANSMISIÓN VERTICAL DEL VIRUS DE LA INFLUENZA A (H1N1): A PROPÓSITO DE UN CASO
}

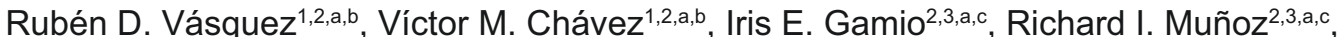 \\ Marcos F. Polar $2,3, a, c$, Raúl Montalvo ${ }^{1,2, d}$, Eduardo Ticona ${ }^{1,2,3, a, b}$
}

\begin{abstract}
RESUMEN
Se reporta el caso de un recién nacido varón, producto de embarazo de 36 semanas, con diagnóstico de neumonía congénita y examen confirmatorio de infección por el virus de la influenza A (H1N1), sin ningún otro tipo de contacto sospechoso. La madre ingresó al hospital con insuficiencia respiratoria y antecedente de proceso gripal de cinco días de evolución, durante los primeros días de la pandemia en el Perú. Por la evolución grave del proceso respiratorio, se le administró ventilación mecánica para luego ser sometida a cesárea por sufrimiento fetal agudo y oligoamnios. Se confirmó en la madre infección por el virus de la influenza A H1N1 epidémico y tuberculosis pulmonar.
\end{abstract}

Palabras clave: Virus de la influenza A subtipo H1N1; Transmisión vertical de enfermedad infecciosa; Trabajo de parto prematuro; Neumonía viral; Sufrimiento fetal (fuente: DeCS BIREME).

\section{PROBABLE VERTICAL TRANSMISSION OF THE INFLUENZA VIRUS A (H1N1): APROPOS OF A CASE}

\begin{abstract}
We report the case of a male newborn, product of a 36 week pregnancy, with diagnosis of congenital pneumonia and with a confirmatory test for influenza A (H1N1) virus, without any other suspicious contact. The mother was admitted to the hospital with respiratory failure and the history of a flu-like episode of 5 days of evolution, during the first days of the pandemic in Peru. Due to the severe evolution of the respiratory process, assisted ventilation was given to her and then a cesarean section was performed due to acute fetal distress and oligoamnios. The mother was later confirmed as a case of epidemic influenza A (H1N1) and pulmonary tuberculosis.
\end{abstract}

Key words: Influenza A virus, H1N1 subtype; Infectious disease transmission, vertical; Obstetric labor, premature; Pneumonia viral; Fetal distress (source: MeSH NLM).

\section{INTRODUCCIÓN}

Desde el inicio de la pandemia del virus de la influenza A (H1N1) en el 2009, más de 70 países han reportando casos de infección humana, cuyo número ha aumentado progresivamente. El primer caso importado diagnosticado en el Perú fue el 15 de mayo de 2009 en una joven peruana que retornó al Perú procedente de Nueva York, mientras que el primer caso autóctono se registró en una mujer el 22 de mayo de 2009; ambas en la ciudad de Lima ${ }^{(1)}$.

En la influenza estacional, existen personas que presentan mayor riesgo de sufrir complicaciones graves relacionadas con esa enfermedad; de la misma manera los primeros reportes de la pandemia actual han establecido que el embarazo, así como enfermedades previamente identificadas, como asma y diabe- tes, tienen un riesgo aumentado de sufrir complicaciones ${ }^{(2)}$.

La gestación es una condición con un riesgo incrementado para el desarrollo de enfermedad grave y muerte por influenza, situación atribuida a los cambios fisiológicos que ocurren durante esta etapa ${ }^{(3)}$, dentro de ellas las alteraciones inmunológicas caracterizadas por un giro inmunológico desde la inmunidad celular hacia la inmunidad humoral, que vuelve a la mujer más susceptible a ciertos agentes virales incluido este virus ${ }^{(4)}$.

La enfermedad subclínica en recién nacidos y lactantes, hijos de madres expuestas a la influenza, se atribuye a la adquisición transplacentaria de anticuerpos protectores -los cuales pueden proporcionar protección por 3 a 6 meses después del nacimiento- así como a la protección brindada por la ingesta de leche materna ${ }^{(5)}$.

\footnotetext{
Servicio de Enfermedades Infecciosas y Tropicales, Hospital Nacional Dos de Mayo. Lima, Perú.

Facultad de Medicina, Universidad Nacional Mayor de San Marcos. Lima, Perú.

Servicio de Neonatología, Hospital Nacional Dos de Mayo. Lima. Perú.

Facultad de Medicina, Universidad San Martin de Porres. Lima, Perú.

Médico cirujano; ${ }^{b}$ Especialista en Enfermedades Infecciosas y Tropicales; ' ${ }^{c}$ Especialista en Pediatría; ${ }^{d}$ Residente en Enfermedades Infecciosas y Tropicales.
}

Recibido: 05-07-10 Aprobado: 25-08-10 


\section{REPORTE DE CASO}

Se describe el caso de un recién nacido (RN) varón pretérmino, de 36 semanas de gestación, nacido por cesárea el 1 de julio de 2009 a las 2.30 horas, por sufrimiento fetal agudo y oligoamnios. El puntaje de APGAR al nacer fue de 4 al minuto, 4 a los cinco minutos y 7 a los diez minutos. EI RN fue adecuado para la edad gestacional, pesó $2,75 \mathrm{~kg}$, hijo de madre con diagnóstico de infección por el virus de la influenza $A(H 1 N 1)$ realizado por la prueba de reacción en cadena de la polimerasa en transcripción reversa (RT-PCR) y tuberculosis pulmonar BAAR positivo, quién desarrolló una insuficiencia respiratoria aguda con compromiso pulmonar grave, permaneció con soporte ventilatorio (Figura 1).

El RN desarrolló neumonía grave e insuficiencia respiratoria por lo que requirió ventilación mecánica. El antecedente de historia gestacional, de la enfermedad actual de la madre y del neonato, así como los exámenes de laboratorio iniciales, establecen la presencia de neumonía congénita (Tabla 1 y Figura 2), ya que no hubo evidencia inicial de distrés respiratorio por prematuridad, ni síndrome de aspiración de liquido amniótico meconial o factores de riesgo para infección bacteriana.
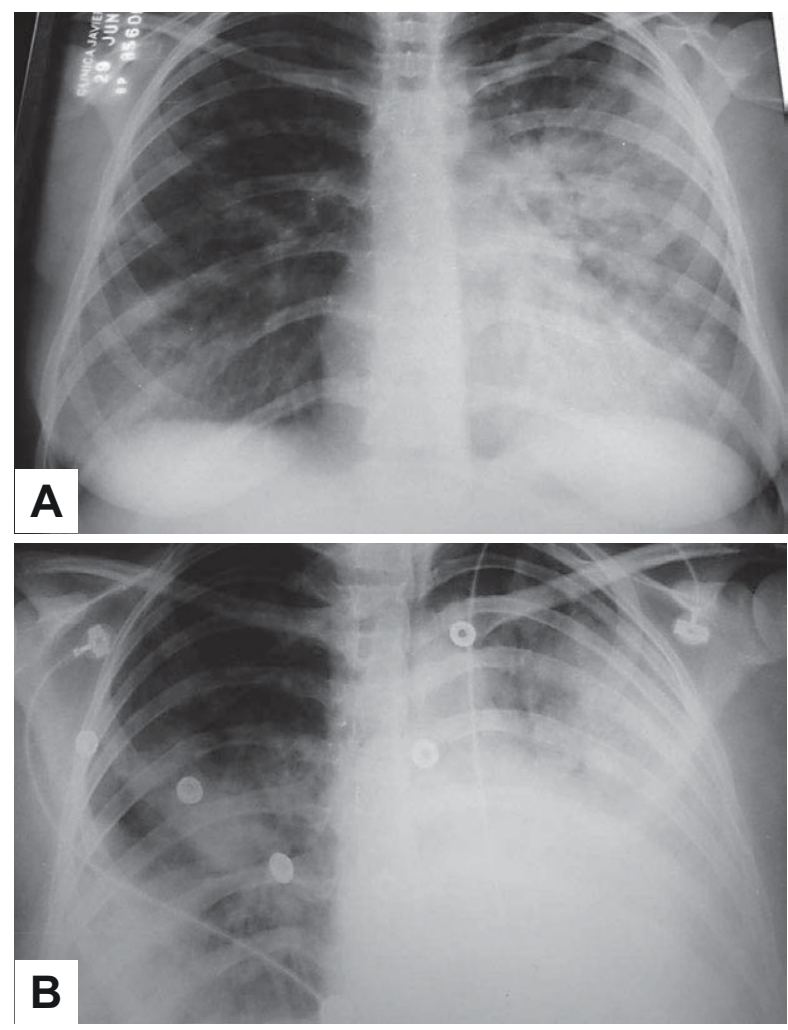

Figura 1. Radiografía de tórax anteroposterior de la madre Muestra imágenes radio-opacas en hemitórax izquierdo el 29 de junio 2009 (A); y en forma bilateral el 30 de junio de 2009 (B).
El RN ingresa a la Unidad de Cuidados Intensivos Neonatales el día 1 de julio, con los diagnósticos de síndrome de distrés respiratorio, depresión neonatal respiratoria y neumonía congénita, se le suministra ventilación mecánica para soporte ventilatorio y también soporte hemodinámico; recibe terapia antimicrobiana

Tabla 1. Principales exámenes de laboratorio realizados.

\begin{tabular}{|c|c|c|}
\hline Análisis & Resul & Itados \\
\hline Hemograma (fecha) & $(01-07-09)$ & $(07-07-09)$ \\
\hline Hemoglobina $(\mathrm{g} / \mathrm{dL})$ & 19,3 & 15,1 \\
\hline Hematocrito $(\%)$ & 54,60 & 42,6 \\
\hline Leucocitos $\left(\mathrm{cel} / \mathrm{mm}^{3}\right)$ & 12190 & 9250 \\
\hline Abastonados (\%) & 0 & 1 \\
\hline Segmentados (\%) & 71 & 54 \\
\hline Eosinófilos (\%) & 1 & 10 \\
\hline Linfocitos (\%) & 25 & 23 \\
\hline Monocitos (\%) & 3 & 12 \\
\hline Plaquetas (cel/mm3) & 163000 & 339000 \\
\hline Bioquímica sanguínea (fecha) & $(01-07-09)$ & \\
\hline Glucosa (mg/dL) & 62 & \\
\hline Calcio $(\mathrm{mg} / \mathrm{dl})$ & 7,7 & \\
\hline Sodio (mEQ/L) & 136 & \\
\hline Potasio (mmol/L) & 4,8 & \\
\hline Cloro (mEQ/L) & 114 & \\
\hline Magnesio (mg/dL) & 1,5 & \\
\hline Urea (mg/dL) & 12,7 & \\
\hline Creatinina (mg/dL) & 1 & \\
\hline TGO U/L & 35 & \\
\hline TGP U/L & 17 & \\
\hline DHL U/L & 1349 & \\
\hline Proteínas totales ( $\mathrm{g} / \mathrm{dl})$ & 4,3 & \\
\hline Albumina (g/dL) & 2,1 & \\
\hline Globulina (g/dL) & 2,2 & \\
\hline Análisis de orina (fecha) & $(03-07-09)$ & \\
\hline Densidad & 1005 & \\
\hline $\mathrm{pH}$ & ácido & \\
\hline Leucocitos & $1-2 \times C$ & \\
\hline Glóbulos rojos & $0-1 \times C$ & \\
\hline Células epiteliales & $0-1 \times C$ & \\
\hline Análisis de gases arteriales (fecha & $(07-07-09)$ & $(07-07-09)^{*}$ \\
\hline $\mathrm{FiO} 2(\%)$ & 35 & 25 \\
\hline $\mathrm{pH}$ & 7,42 & 7,41 \\
\hline $\mathrm{pCO} 2(\mathrm{mmHg})$ & 19,8 & 28 \\
\hline $\mathrm{pO} 2(\mathrm{mmHg})$ & 154 & 103 \\
\hline $\mathrm{HCO} 3(\mathrm{Mmol} / \mathrm{L})$ & 13,2 & 18,3 \\
\hline $\mathrm{G}(\mathrm{A}-\mathrm{a}) \mathrm{O} 2$ (Mmol/L) & 52 & 27,5 \\
\hline $\mathrm{Pa} / \mathrm{Fi} \mathrm{O} 2 \mathrm{mmHg} / \%$ & 426 & 426 \\
\hline Diagnóstico microbiológico & Resultado & Fecha \\
\hline Hemocultivo & Negativo** & $01 / 07 / 2009$ \\
\hline RT-PCR influenza $A(\mathrm{H} 1 \mathrm{~N} 1)^{\star \star *}$ & Positivo & $02 / 07 / 2009$ \\
\hline BAAR y cultivo ${ }^{* * *}$ & Negativo & $04 / 07 / 2009$ \\
\hline
\end{tabular}

* Seis horas posteriores al primer examen de gases arteriales

** A los siete días.

*** Muestra de aspirado nasofaríngeo.

${ }^{* * * *}$ En aspirado gástrico. 


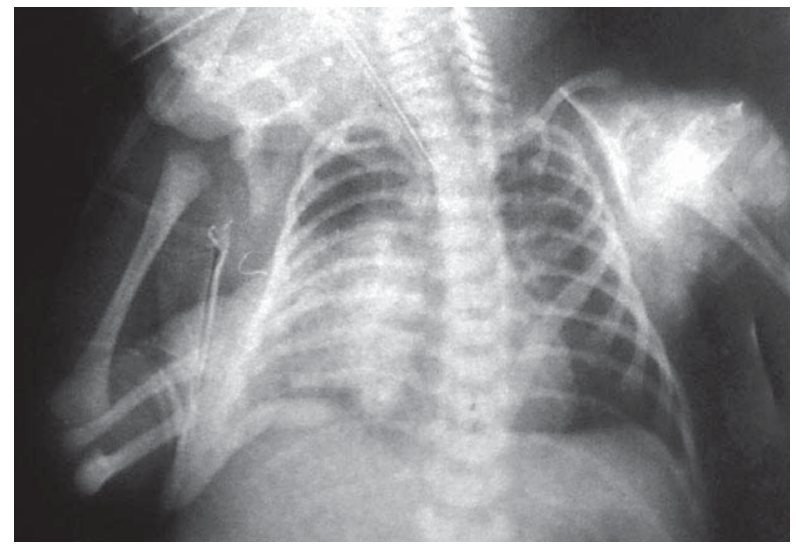

Figura 2. Radiografía de tórax anteroposterior del neonato del 01 de julio de 2009, que muestra imagen radio-opaca de bordes limitados con broncograma aéreo en mitad inferior de hemitórax derecho.

empírica (una hora después del nacimiento) con ampicilina $210 \mathrm{mg}$ cada 12 horas vía endovenosa y cefotaxima $138 \mathrm{mg}$ cada 12 horas vía endovenosa. Se toma una muestra de hisopado nasofaríngeo a las 24 horas de nacido para confirmar presencia del virus de la influenza $A(\mathrm{H} 1 \mathrm{~N} 1)$, se agrega tratamiento antiviral con oseltamivir $12 \mathrm{mg}$ cada 12 horas por vía oral, iniciado a las 35 horas del nacimiento.

Al cuarto día de nacido, se recibe el informe de RT-PCR en tiempo real para el virus de la influenza $A(H 1 N 1)$, con resultado positivo. EI RN, por la gravedad de su estado de salud (problema de depresión respiratoria y posterior síndrome de distrés respiratorio agudo), no tuvo, en ningún momento, contacto con la madre.

EI RN evolucionó favorablemente, dejó la ventilación mecánica el día 03 de julio y salió de alta a los 12 días de vida.

\section{DISCUSIÓN}

La presente descripción corresponde al primer caso en el Perú de un recién nacido diagnosticado de neumonía congénita causado por la infección del virus de la influenza A (H1N1), por probable transmisión transplacentaria; hasta el momento del sometimiento del presente manuscrito al proceso editorial, no existen reportes en la literatura médica de transmisión vertical de dicho virus en el mundo.

Existen pocos estudios con relación a influenza y gestación, siendo muchos de ellos contradictorios. Estudios preliminares en roedores con influenza, reportaban hallazgos virológicos e histopatológicos que demostraban daños en el endometrio, placenta y en el feto, fundamentalmente en el hígado y tracto respiratorio fetales (11). Posteriores hallazgos demostraron que la infección prenatal por influenza en roedores puede producir cambios histopatológicos en el cerebro y alteraciones de la conducta en el recién nacido, sin embargo, y debido a que el ARN del virus influenza no fue detectado en el cerebro del feto, estos cambios sugieren que los efectos podrían ser secundarios a la fiebre ${ }^{(6,10)}$ o respuesta inflamatoria materna, antes que resultado de un efecto viral directo ${ }^{(7-9)}$. La relevancia de estos hallazgos en gestantes humanas es discutible ${ }^{(11)}$.

La viremia es rara en la influenza estacional y la transmisión transplacentaria parece ser muy infrecuente; esta vía solamente ha sido demostrada en cepas altamente patógenas, como la influenza aviar H5N1, ello se reporta en estudios post mórtem en una gestante fallecida por infección con el virus de la influenza aviar y el hallazgo de secuencia genómica viral de influenza aviar H5N1 en células citotrofoblásticas de la placenta, así como en el pulmón, células mononucleares circulantes y macrófagos del hígado del feto ${ }^{(12,13)}$. Aun en ausencia de transmisión transplacentaria, los efectos sobre el feto podrían ser secundarios a la respuesta inflamatoria materna, antes que el resultado de un efecto viral directo.

En el caso reportado, se obtuvo una muestra de hisopado nasal, con una prueba de PCR positiva para el virus de la influenza $A(H 1 N 1)$-con sensibilidad y especificidad superiores a $95 \%$ - en un recién nacido, es preciso mencionar que las evaluaciones clínicas, hematológicas, bioquímicas y radiológicas no mostraron evidencia de compromiso de otros órganos.

La falta de evidencia clara o sospecha clínica, probablemente retrasó el inicio de la terapia antiviral específica, pues recibió inicialmente tratamiento antimicrobiano de amplio espectro y, posteriormente, ante la sospecha de neumonía debida al virus de la influenza A (H1N1) se inició el tratamiento con oseltamivir, en ese sentido, la decisión temprana de su administración, probablemente haya influenciado en el pronóstico favorable de este caso, sin embargo, no es posible verificarlo ya que también recibió tratamiento antibiótico de amplio espectro.

La no realización de exámenes complementarios (aislamiento viral, hallazgos histopatológicos) en la placenta, constituye la principal limitación para una mejor documentación de este caso. No obstante, la evolución clínica del paciente, la respuesta al tratamiento antiviral, los resultados negativos para otras enfermedades (BAAR en aspirado gástrico, así como el cultivo posterior, negativos) hacen poco probable la posibilidad diagnóstica de tuberculosis congénita; así mismo, el 
estado de estrés materno previo y la edad gestacional del RN, alejan la posibilidad de que el cuadro clínico del paciente pudiera corresponder a manifestaciones de prematuridad tardía.

Finalmente, consideramos a este como el primer caso de transmisión vertical del virus de la influenza $A(\mathrm{H} 1 \mathrm{~N} 1)$ en el Perú, con evolución exitosa.

La información existente ${ }^{(14,15)}$, así como este reporte, demuestran que es posible la transmisión vertical del virus de la influenza $A(\mathrm{H} 1 \mathrm{~N} 1)$, y probablemente de otros tipos de virus de influenza, por lo cual es importante considerar dentro de las posibilidades etiológicas de las neumonías congénitas en todo RN cuya madre presente un cuadro clínico compatible con influenza, para iniciar el tratamiento antiviral en forma precoz.

\section{Fuente de Financiamiento}

Autofinanciado.

\section{Conflictos de Interés}

Los autores declaran no tener conflictos de interés en la elaboración ni publicación de este artículo.

\section{REFERENCIAS BIBLIOGRÁFICAS}

1. Dirección General de Epidemiología, Ministerio de Salud (MINSA). Vigilancia de la influenza. Influenza A (H1N1) [Página de Internet]. Lima: MINSA; 2009. [Fecha de acceso: 20 de junio de 2010] Disponible en: http://www. dge.gob.pe/influenza/AH1N1/index.php?u=Acb52rszrd

2. Centers for Disease Control and Prevention CDC. H1N1 Flu [Página de Internet]. Atlanta: CDC; 2010. [Fecha de acceso: 20 de junio de 2010] Disponible en: http://www.cdc. gov/h1n1flu/

3. Goodnight WH, Soper DE. Pneumonia in pregnancy. Crit Care Med. 2005;33(10 Suppl):S390-97.

4. Jamieson DJ, Theiler RN, Rasmussen SA. Emerging infections and pregnancy. Emerg Infect Dis. 2006;12(11):1638-43.

5. Wilkinson DJ, Buttery JP, Andersen CC. Influenza in the neonatal intensive care unit. J Perinatol. 2006;26(12):772-76.
6. Irving WL, James DK, Stephenson T, Laing P, Jameson C, Oxford JS, et al. Influenza virus infection in the second and third trimesters of pregnancy: a clinical and seroepidemiological study. BJOG. 2000;107(10):1282-89.

7. Fatemi SH, Earle J, Kanodia R, Kist D, Emamian ES, Patterson $\mathrm{PH}$, et al. Prenatal viral infection leads to pyramidal cell atrophy and macrocephaly in adulthood: implications for genesis of autism and schizophrenia. Cell Mol Neurobiol. 2002;22(1):25-33.

8. Shi L, Fatemi SH, Sidwell RW, Patterson PH. Maternal influenza infection causes marked behavioral and pharmacological changes in the offspring. J Neurosci. 2003;23(1):297-302.

9. Shi L, Tu N, Patterson PH. Maternal influenza infection is likely to alter fetal brain development indirectly: the virus is not detected in the fetus. Int J Dev Neurosci. 2005;23(23):299-305.

10. Czeizel AE, Puhó EH, Acs N, Bánhidy F. High feverrelated maternal diseases as possible causes of multiple congenital abnormalities: a population-based case-control study. Birth Defects Res A Clin Mol Teratol. 2007;79(7):54451.

11. Rushton DI, Collie MH, Sweet C, Husseini RH, Smith H. The effects of maternal influenzal viraemia in late gestation on the conceptus of the pregnant ferret. J Pathol. 1983;140(3):181-91.

12. Gu J, Xie Z, Gao Z, Liu J, Korteweg C, Ye J, et al. H5N1 infection of the respiratory tract and beyond: a molecular pathology study. Lancet 2007;370(9593):1137-45.

13. Jamieson DJ, Honein MA, Rasmussen SA, Williams JL, Swerdlow DL, Biggerstaff MS, et al. H1N1 2009 influenza virus infection during pregnancy in the USA. Lancet. 2009;374(9688):451-58.

14. Worldnews Network. Baby born in Thailand infected with H1N1 [Página en Internet]. New York: Worldnewsnetwork; c2010. [Fecha de acceso: 20 de mayo de 2010] Disponible en: http://article.wn.com/view/2009/07/28/Baby_born_in_ Thailand_infected_with_H1N1_w/

15. Zou S. Potential impact of pandemic influenza on blood safety and availability. Transfus Med Rev. 2006;20(3):181-89.

Correspondencia: Rubén Darío Vásquez Becerra. Dirección: Parque "Historia de la Medicina Peruana" s/n Alt. Cdra. 13 Av. Grau. Lima 1, Lima, Perú.

Teléfono: (511) 328-0028

Correo electrónico: ruben_dariovb@yahoo.es 